University of Nebraska - Lincoln

DigitalCommons@University of Nebraska - Lincoln

\title{
A Landscape Perspective in Managing Vegetation for Beneficial Plant-PestNatural Enemy Interactions: a Foundation for Areawide Pest Management
}

\author{
Michael J. Brewer \\ Michigan State University, michael.j.brewer@noaa.gov \\ Takuji Noma \\ Michigan State University \\ Norman C. Elliott \\ United States Department of Agriculture-Agricultural Research Service, norman.elliott@ars.usda.gov
}

Follow this and additional works at: https://digitalcommons.unl.edu/usdaarsfacpub

Part of the Agricultural Science Commons

\footnotetext{
Brewer, Michael J.; Noma, Takuji; and Elliott, Norman C., "A Landscape Perspective in Managing Vegetation for Beneficial Plant-PestNatural Enemy Interactions: a Foundation for Areawide Pest Management" (2008). Publications from USDA-ARS / UNL Faculty. 648.

https://digitalcommons.unl.edu/usdaarsfacpub/648
}

This Article is brought to you for free and open access by the U.S. Department of Agriculture: Agricultural Research Service, Lincoln, Nebraska at DigitalCommons@University of Nebraska - Lincoln. It has been accepted for inclusion in Publications from USDA-ARS / UNL Faculty by an authorized administrator of DigitalCommons@University of Nebraska - Lincoln. 


\title{
A Landscape Perspective in Managing Vegetation for Beneficial Plant-Pest- Natural Enemy Interactions: a Foundation for Areawide Pest Management
}

\author{
MiChAEL J. BREWER, ${ }^{1}$ TAKUJI NOMA ${ }^{1}$ AND \\ NORMAN C. ELLIOTT² \\ 'Integrated Pest Management Program, Department of Entomology, \\ Michigan State University, East Lansing, Michigan, USA \\ ${ }^{2}$ US Department of Agriculture, Agricultural Research Service, Stillwater, \\ Oklahoma, USA
}

\section{Introduction}

In the USA, Europe and increasingly in other regions, cropping systems designed for high production output are significant features of the landscape. Deployment of mechanized and high-input cropping systems over the last 50 years has resulted in substantial transformation and fragmentation of major grassland, shrubland and woodland systems throughout the world. These cropping systems are typically less diverse in species composition, structure and ecological functioning than those found in the original plant community (Altieri, 2004). Decreases in plant diversity of agroecosystems (i.e. the crops themselves and surrounding remnants of the original plant system) have negatively affected ecosystem functions (Freemark, 2005). For agriculture, declines in agroecosystem diversity can result in increased crop herbivory and decreased beneficial organisms that feed on pests (Letourneau, 1998; Altieri, 2004).

Agricultural plant diversification is advocated as a remediation method to reverse these pest management challenges associated with modern cropping systems (Banks, 2000; Benton et al., 2003; Altieri, 2004; Schmidt et al., 2004), adding to other efforts to restore disturbed areas to their original plant community (Freemark, 2005). Mechanistically, this approach is based in part on outcomes of vegetation-driven plant-herbivore--natural enemy interactions predicted from the resource concentration, 
enemies, associational resistance and plant apparency hypotheses (Root, 1973; Banks, 2000; Altieri, 2004).

A landscape perspective can help refine vegetative-based management approaches to pest management locally within, or adjacent to, agricultural fields of interest (e.g. Vorley and Wratten, 1987; Murphy et al., 1996; Banks, 2000). More recently, landscape ecologists have assessed the health of ecosystem services involving insects across vegetative conditions that extend to the neighbourhood and broader landscape (e.g. Kruess and Tscharntke, 1994; Marino and Landis, 1996; Duelli, 1997; Elliott et al., 1998b; Fahrig and Jonsen, 1998; Thies et al., 2005). In the young field of landscape ecology, studies of the effects of landscape elements on arthropod natural enemies of pest insects have come from predominantly forested regions that have been fragmented to various degrees by forest harvesting and other human activities (e.g. Roland and Taylor, 1997), while some studies consider crop-woodland landscapes (e.g. Menalled et al., 1999) and, much less commonly, crop-grassland/shrubland landscapes (e.g. Elliott et al., 1998a). Adding a landscape perspective provides ecosystem context in which plant-pest-natural enemy (PPNE) interactions must function, with more regional effects possibly impeding, enhancing or not affecting outcomes of species interactions at the lower organizational level of individual fields (Noss, 1990).

In a companion chapter, Byrne (this volume, Chapter 4) focused on dispersal and migration of insects and their importance in understanding the dynamics of pest spread across agroecosystems. We broaden the discussion to consider the relationships of PPNE interactions to vegetation, ranging from vegetation within agricultural fields (e.g. Nentwig, 1989), adjacent boundaries and fields (e.g. Vorley and Wratten, 1987; Dennis et al., 2000) and in the broader landscape (e.g. Marino and Landis, 1996; Elliott et al., 1998b; Thies et al., 2005). Here, we pay special attention to examples from crop-grassland/shrubland landscapes to complement previous reviews and perspectives on crop-woodland and -forest landscapes (Roland and Taylor, 1997; Menalled et al., 1999). Others have considered a landscape perspective to areawide application of mating disruption techniques (i.e. pheromone and sterile-male techniques) (Jones and Casagrande, 2000). A review of landscape characteristics and principles applicable to management of pests is provided.

We also introduce landscape analysis approaches for characterizing and assessing landscape composition, structure and scale of vegetation relevant to PPNE interactions. Throughout, we use a case example on regulation of cereal aphids by natural enemies in North America, and supplemental examples of similar PPNE systems in Europe. We propose that understanding of the role of vegetation in PPNE interactions increases with a landscape perspective and positions practitioners to best apply vegetation-based approaches in pest management, both locally and areawide.

\section{A Landscape Perspective to Improve Pest Management}

\section{Composition of landscape elements}

A landscape perspective of pest management considers PPNE interactions within the context of landscape elements, emphasizing vegetation as a principal element affecting 
these interactions (Banks, 2000; Altieri, 2004). Species lists of herbivores (key pests and possibly those causing incidental herbivory), their natural enemies, their host plants and the biological resources available for pests and natural enemies, along with their physiological and behavioural traits, are relevant to considering how biological control functions (Letourneau, 1998). Likewise, characteristics of crop cultivars, non-crop plants and pest variants in plant virulence are relevant in assessing how vegetation can reduce pest feeding and damage (Banks, 2000). One friendly addition to these details is the characterization of relevant abiotic conditions. Plants, herbivores and natural enemies, especially in temperate systems, must function within the temperature and moisture ranges of the region of interest and may provide clues to development and reproduction of pests and natural enemies (Jervis, 2005).

Species lists, species characterization and abiotic conditions allow initial cataloguing of PPNE interactions relevant to pest management. Yet estimations of presence and intensity of species, their traits and abiotic conditions in field studies are labour and knowledge intensive. For field assessment, key questions are: what compositional details are essential to gather and what surrogate measurements are reliable to gauge beneficial PPNE functioning (Duelli, 1997)? The extensive agricultural ecology literature provides a foundation to make judicious selection of key species, biological resources and abiotic conditions for measurement. After initial surveys and consultation of the literature, representatives of key taxa may be selected to measure abundance as an indicator of health of PPNE interactions. None the less, the diversity of pest and beneficial organism fauna and their interactions present challenges to predicting pest management outcomes (Sheehan, 1986).

\section{Structure of landscape elements}

Inclusion of vegetation structure can greatly help in understanding pest regulation. Structure of the ecosystem is delineated by the arrangement of land elements (e.g. hills, waterways, soil types, roadways) and the managed and unmanaged biological elements (e.g. arrangement of agricultural fields and borders, and non-crop patches and corridors). Standardized landscape metrics can be used to characterize patch size, spatial arrangement of vegetation patches and corridors, and the degree of saturation and mixing of vegetation types across a landscape (Elliott et al., 1988a). Temporal patterns of cultivation of managed plants and the growth period of unmanaged plants are also relevant to understanding PPNE interactions, especially in temperate climates (Wissinger, 1997; Barbosa, 1998). Structural and temporal details have been used in qualitative assessments of PPNE interactions (e.g. Vorley and Wratten, 1987; Cowgill et al., 1993; Murphy et al., 1996; Ahern and Brewer, 2002), but their use in a quantitative assessment has been a more recent development.

Methodology to calculate landscape metrics from mapping products and insert them within an analytical framework to assess their relationship to PPNE interactions is improving as remote sensing and geographic information system (GIS) tools are applied. The process of gathering remotely sensed imagery from appropriate sensors for vegetation classification and classification into pertinent vegetation layers 
Table 5.1. Percentages of various land cover types in heterogeneous and homogeneous vegetation regions surrounding wheat production farms of the wheat-growing west-central region of the Great Plains of North America.

\begin{tabular}{lccr}
\hline & \multicolumn{2}{c}{ Regional-scale diversity $(\%)$} & \\
\cline { 2 - 3 } Land cover & Heterogeneous & Homogeneous & Accuracya \\
\hline Grass-based vegetation & $52.93(3.00)^{\mathrm{g}}$ & $74.38(3.98)^{\mathrm{h}}$ & \\
Wheat & $12.56(2.40)$ & $18.62(4.41)$ & 77.78 \\
CRP grassland & $19.09(1.70)$ & $22.76(4.93)$ & 79.55 \\
Other grassland & $21.27(5.44)$ & $33.99(8.45)$ & 76.79 \\
Non-grass vegetation & $32.60(1.84)^{\mathrm{g}}$ & $7.95(1.42)^{\mathrm{h}}$ & \\
Sunflower & $8.98(4.15)$ & $1.26(0.60)$ & 50.00 \\
Lucerne & $6.39(1.72)$ & $0.76(0.36)$ & 95.45 \\
Maize & $1.52(1.07)$ & $0.29(0.21)$ & 68.75 \\
Millet & $0.21(0.16)$ & $0.11(0.06)$ & 100.00 \\
Other vegetation & & $2.92(0.68)$ & 52.17 \\
Riparian area & $11.64(1.45)$ & $2.61(0.69)$ & 100.00 \\
Grass/non-grass ratio $^{\mathrm{d}}$ & $3.87(1.52)$ & $15.75(5.95)^{\mathrm{h}}$ & \\
Other land cover $^{\mathrm{h}}$ & $1.68(0.15)^{\mathrm{g}}$ & $17.67(4.31)$ & 77.08 \\
\hline
\end{tabular}

The numbers are a mean percentage of the total patch areas (standard error) occupied by each land cover type within $25 \mathrm{~km}^{2}$ circular areas represented in the region $(n=8$ for each landscape type). Different letters within a row indicate a significant difference at $\alpha=0.05$. aAccuracy of classification in matching randomly selected classified pixels on the thematic map, based on ground-truth surveys.

${ }^{b}$ Grasslands managed for wildlife conservation, as sponsored by the US Department of Agriculture Conservation Reserve Program (Mitchell, 1988).

'Grasslands managed principally for cattle grazing.

dPatches consisting largely of unclassified crop or weedy vegetation.

ePatches consisting largely of shrubs and trees along a body of water.

fA combination of non-vegetation land cover types (fallow, urban and water) that was excluded from analysis.

The land cover classification was used to select a vegetation gradient that represented extant farm-scale plant diversity that was being managed by wheat farmers and regional-scale diversity that was affected by acreage allotments to farmers participating in a conservation programme of the US Department of Agriculture (i.e. Conservation Reserve Program (Mitchell, 1988)). In simple farms, the crop rotation was a series of spatially alternating wheat and fallow strips of $30-60 \mathrm{~m}$ in width (wheat-fallow). In diverse farms, the cropping area consisted of a series of wheat, alternative spring-sown crop and fallow strips (wheat-alternate crop-fallow) (see Fig. 5.1). The regional-scale landscapes were selected to represent relatively heterogeneous or homogeneous regions in which farm sites were nested based on degree of grass-based vegetation.

We used $25 \mathrm{~km}^{2}$ circular regions (5.6 $\mathrm{km}$ diameter) with the farm as proximate centre to evaluate the regional vegetation. Within each circle, total patch areas for 
each vegetation class on the thematic map were quantified using FRAGSTATS (McGarigal and Marks, 1995). Based on the thematic map, the patch area surrounding the farm sites was classified as either heterogeneous or homogeneous in regionalscale vegetation diversity (see Fig. 5.1, Table 5.1). The homogeneous regions consisted of relatively large areas of grass-based vegetation (combination of wheat, Conservation Reserve Program grasslands and other grasslands) and small areas of non-grass vegetation (combination of other agriculture and riparian areas), while the heterogeneous regions consisted of relatively small grass-based vegetation and large non-grass vegetation (see Table 5.1). Through this process we categorized four combinations of farm-scale and regional-scale diversity in the $14,000 \mathrm{~km}^{2}$ study area, as linked to two scales appropriate to farm-level management and regional agricultural programme management (see Fig. 5.1).

As a note of caution, quality of classification of land cover (e.g. plant species, non-crop land management type, crop type) varies considerably across mapping products. In our example the classifications were derived from satellite imagery. We acknowledge that the mechanics of classification into pertinent vegetation layers can be laborious and require specialized computing, software and human resources (Elliott et al., 1998a). Standardized mapping products with refined crop and vegetation data layer information are welcome tools, and are becoming more widely available (USDA, 2007). We anticipate that high-quality, standardized cropland data layer products will facilitate the broader use of structure of vegetation in understanding PPNE interactions. Low-altitude photography has also been used, and its finer grain may be useful in identifying vegetation corridors and other landscape features that are not easily differentiated from satellite imagery (Jensen, 2000).

\section{Function of landscape elements}

Plant-pest-natural enemy interactions can be affected by structural and temporal patterns of vegetation in the ecosystem. In general, the composition, grain size and spatial and temporal arrangement of the vegetation - and, potentially, other elements that comprise a landscape - may play important roles in determining an organism's population size. For agricultural pests, studies have shown that parasitism and predation rates on pest insects tend to be higher and crop damage lower in structurally diverse agricultural landscapes than in simplified landscapes (Menalled et al., 1999; Altieri, 2004), although this is not a certain outcome across systems (Sheehan, 1986). This relationship is probably not the result of landscape diversity per se, but rather depends on whether specific requisites of natural enemies, as well as pests, are more or less likely to be present and accessible in a diverse spatial mosaic of habitats than in a landscape with few habitat types that are accessible to natural enemies (Menalled et al., 1999). This assumption is consistent with hierarchy theory, in which higher organizational levels (i.e. composition and structure of vegetation of an area) constrain the interactions at lower levels (i.e. specific PPNE interactions in a cropped field) (Noss, 1990). From a landscape perspective, the metrics of key and surrogate elements may serve as important indicators of the health of PPNE interactions.

From a practitioner's viewpoint, if only a few compositional elements are key to pest management in a simple landscape structure (e.g. a widely planted monoculture 
that dominates the landscape), then understanding of key mechanistic functions driving the interaction may be sufficient to evaluate approaches to pest management. For example, when the organisms have limited or highly preferred biological resources to use along with limited mobility, mechanistic approaches may reveal opportunities to manage a few key vegetation elements in order to improve ecological functioning of biological control agents.

A landscape perspective is still relevant, particularly if movement between resources is needed (Wissinger, 1997), and a qualitative assessment may be completely satisfactory. Through use of baffled water traps to detect parasitoid movement, Vorley and Wratten (1987) found that barley and early-sown wheat adjacent to late-sown wheat served as a significant source of hymenopteran parasitoids (Aphidius spp.) to control potentially damaging levels of cereal aphids populating late-sown wheat. Also in England, Cowgill et al. (1993) found that flowering, noncrop plants next to cereal crops increased the abundance of adults and eggs of the syrphid Episyrphus balteatus (Degeer) in winter wheat. In the USA, Ahern and Brewer (2002) found that addition of spring-sown sunflower into a strip rotation of winter wheat and fallow increased the abundance of several hymenopteran parasitoids (Braconidae and Aphelinidae) that attack the key cereal aphid, Diuraphis noxia (Mordvilko). And, as an example outside the cereal aphid system, Murphy et al. (1996) found that early-season abundance of an egg parasitoid, Anagrus epos (Girault), of the grape leafhopper increased twofold when prune trees were near vineyards. The landscape features of proximity, prevailing wind direction and seasonality of biological resources were key compositional, physiological and behavioural attributes of these studies.

When multiple compositional, physiological and behavioural attributes are relevant (e.g. broad host ranges, multiple biological resources, high mobility, varied abiotic conditions), both composition and structure of vegetation elements may affect PPNE interactions. It is this situation where a landscape quantitative assessment may be most valuable in assessing the relative importance of vegetation structure to PPNE interactions. If there are common relevant features or surrogates to a larger relevant group of compositional elements that can be classified, landscape analysis techniques may help assign (at least in sign if not in intensity) probable pest management-based outcomes. For example, both Thies et al. (2005) in Germany and Menalled et al. (1999) in the USA found that complex landscapes were associated with higher parasitism of herbivores in agricultural lands than in agricultural lands nested in simpler regional vegetation.

It is the potential for multifactor interactions that makes a solely mechanistic approach to devising vegetation management recommendations prone to difficulties in assessing interactions experimentally and prone to unexpected consequences. As an example, lack of improvement of pest management services or even undesirable outcomes, such as increased pest pressure, are possible if the addition of vegetation elements benefits the pest organisms and overshadows benefits to plant or natural enemy regulation of the pests. This concern may be particularly relevant when managing polyphagous and mobile pests with specialized and less mobile natural enemies. In England, Vorley and Wratten (1987) recognized that the benefit of early-sown grains to increase parasitoids must be balanced against the potential increased risk of barley yellow dwarf virus in the cereal-based system. 
In Germany, Thies et al. (2005) noted that the increases in cereal aphid parasitism in complex landscapes were offset by higher aphid colonization in the same complex landscapes.

\section{Scale and pattern of landscape elements}

The effects of spatial scale and temporal patterns of landscape elements on PPNE interactions are more recently appreciated topics in conservation biological control (Letourneau, 1998) and the deployment of cropping system strategies (Helenius, 1997; Benton et al., 2003). As noted above, functioning of PPNE interaction may be associated with the structure and composition of within-field vegetation (e.g. Nentwig, 1989; Ahern and Brewer, 2002), adjacent agricultural fields and field borders (Vorley and Wratten, 1987; Cowgill et al., 1993), and the broader regional structure of remnants of the original plant community and managed cropped and noncropped areas (Marino and Landis, 1996; Elliott et al., 1998b; Letourneau, 1998).

In addition, the seasonal nature of natural and managed vegetation (temporal vegetation structure), especially in temperate zones, may have a strong effect on PPNE interactions (Wissinger, 1997; Barbosa, 1998). In addition, one or more spatial scales from highly local arrangements of specific plant species to more regional arrangement of general vegetation classes (e.g. mixes of plant communities and cropped fields) may affect the functioning of PPNE interactions. More defined scale and magnitude of landscape effects are most probably related to the organism's habitat and foraging characteristics (Dunning et al., 1992; Fahrig and Merriam, 1994). It follows that species with different needs and behaviours will be affected differently by the scale in landscape structure brought about by natural processes, such as disturbance and succession, or by humans, such as cropping system deployment and implementation of vegetation-based farm practices.

In our North American cereal aphid example (see Fig. 5.2, Table 5.2), two dominant parasitoids, Aphelinus albipodus Hayat \& Fatima (Hymenoptera: Aphelinidae) and Lysiphlebus testaceipes (Cresson) (Hymenoptera: Braconidae, Aphidiinae), differ in physiological and behavioural attributes (see Table 5.2).

These biological characteristics may be useful in deriving hypotheses on the relative responsiveness of parasitoids to changes in farm- and regional-scale plant diversity found throughout the wheat production area of this region (see Fig. 5.1). Based on these attributes, a reasonable hypothesis is that $L$. testaceipes would be more sensitive to neighbourhood and regional plant diversity because of its mobility, large host aphid range and adult food requirements. The responsiveness of $A$. albipodus, a representative Aphelinus sp., to plant diversity may not extend beyond the farm-scale strategy to add a spring-sown grain to the traditional wheat-fallow strip rotation. Aphelinus spp. are less mobile, have a smaller host aphid range and can feed on aphid hosts more effectively than $L$. testaceipes. Alternatively, these differences may not be sufficiently large to show differential responses between the species to the two agricultural landscape scales of interest: farm-scale plant diversity managed by wheat farmers and regional-scale diversity affected by acreage allotments to farmers participating in a federally sponsored conservation programme. The dilemma for pest managers is that they work with a diverse fauna, both in composition (number of species) and in the 
(a)

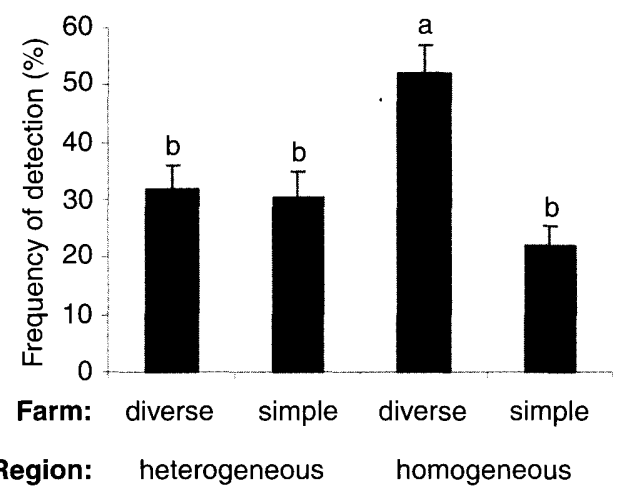

(b)

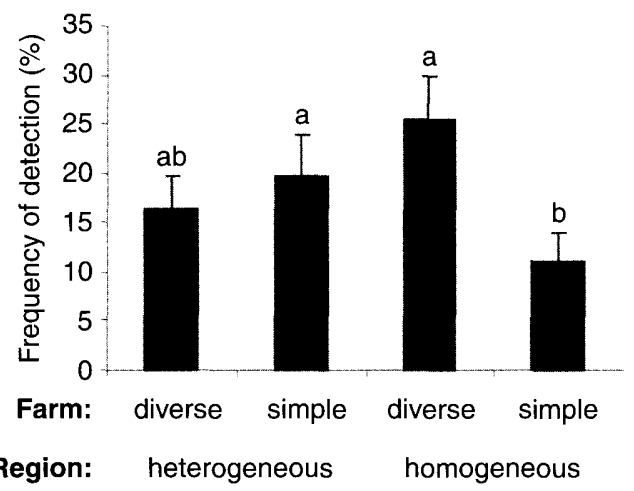

Fig. 5.2. Two experimental designs for analysing the effects of scale heterogeneity on populations: (a) factorial design ( $2 \times 2$ factor design shown here) allowing estimates of relative and joint contributions of local (farm) and regional (areawide) spatial scales of special interest; and (b) regression approach (special-interest local zone surrounded by differing regional conditions shown here) allowing estimates of scale most relevant to ecological functioning of organisms of interest in the local zone.

Table 5.2. The range of physiological and behavioural attributes of two hymenopteran parasitoids (Lysiphlebus testaceipes and Aphelinus sp.) that prey upon Diuraphis noxia and other aphids in the west-central region of the North American Great Plains.

\begin{tabular}{|c|c|c|}
\hline \multirow[b]{2}{*}{ Biological characteristic } & \multicolumn{2}{|c|}{ Parasitoid } \\
\hline & L. testaceipes & Aphelinus sp. \\
\hline Mobility & $\begin{array}{l}\text { Moderate mobility - } \\
\text { flight is common }{ }^{\text {a }}\end{array}$ & $\begin{array}{l}\text { Low mobility - } \\
\text { mostly by walking }\end{array}$ \\
\hline $\begin{array}{l}\text { Response to } \\
\text { attractants }\end{array}$ & $\begin{array}{l}\text { Prey and plant } \\
\text { volatiles }^{c}\end{array}$ & $\begin{array}{l}\text { Less known, less indication } \\
\text { of response to volatiles }{ }^{d}\end{array}$ \\
\hline Host range & More host species ${ }^{e} f$ & Fewer host species, $g$ \\
\hline Adult food sources & $\begin{array}{l}\text { No aphid host feeding, } \\
\text { aphid honeydew }\end{array}$ & $\begin{array}{l}\text { Aphid host feeding, aphid } \\
\text { honeydew }^{i}\end{array}$ \\
\hline
\end{tabular}

aFernandes et al. (1997); ' Mason and Hopper (1997); ' Schuster and Starks (1974); dDe Farias and Hopper (1997); 'Pike et al. (2000); 'Kaiser et al. (2007); 9Elliott et al. (1999); ' $Q u i c k e$ (1997); 'Boyle and Barrows (1978).

variety of physiological needs and behaviours, and a diverse agricultural landscape. This diversity nevertheless provides opportunities to optimize management approaches, locally and areawide.

The composition and quality of a plant community across a landscape both change seasonally with plant phenology and cultivation practices, especially in the 
temperate agricultural regions of the world. In our North American Great Plains cereal aphid example, winter wheat strips are mature or harvested during summer, resulting in a greatly reduced function as habitats of cereal aphids and aphid parasitoids (Brewer et al., 2005). During this time period, spring-sown crops and some non-crop plants in grasslands are available, some of which harbour aphids known to be used by parasitoids of $D$. noxia (Donahue et al., 2000; Brewer et al., 2005). In contrast, wheat strips harbour aphids in the spring, when spring-sown crop plants are not available (Brewer et al., 2005). Thus, quality and relative suitability of wheat strips and other vegetation as habitats of aphid and aphid parasitoids change as seasons progress. Increasing cereal aphid parasitoids early in the season by planting early-sown cereals adjacent to late-sown cereals (Vorley and Wratten, 1987) is another example where temporal patterns in landscape elements may play important roles in PPNE interactions.

\section{Analytical Approaches to Discerning Local and Regional Landscape Effects}

The use of landscape analysis methods in discerning the relevance of scale and pattern of vegetation provides great opportunity to transition to a more quantitative assessment for planning cropping system deployment and adoption of vegetation-based farm practices, both locally and areawide (Elliott et al., 1998b; Thies et al., 2005). In our North American Great Plains cereal aphid example, the classification of farm-scale diversity and regional-scale diversity reflected the extant variation in wheat production (crop strip rotation) and regional agricultural land use in the west-central Great Plains of North America. The large study region allowed consideration of scale effects through a factorial design. For this study, scales are nested in each other: two types of crop strip rotations used on farms are nested in regional agricultural land use that we categorized in two classes. All possible combinations of the levels within each scale of interest were considered in this $2 \times 2$ (farm-scale diversity $\times$ regional-scale diversity) factorial (see Fig. 5.3a). The factorial structure was appropriate in assessing the joint effects of the two landscape scales on the abundance of the two primary parasitoids of the key wheat-damaging aphid.

Our farm scale was within the range of scales found by Vorley and Wrattn (1987) and Thies et al. (2005) to be significant to cereal aphid parasitoid functioning. Our regional scale was designed to capture surrounding vegetation patches which are typically perceived in US land survey units of $1.6 \times 1.6 \mathrm{~km}$ squares (sections) to $9.6 \times 9.6 \mathrm{~km}$ squares (townships) for land use planning (such as the Conservation Reserve Program) and gathering of agricultural land use statistics (Elliott et al., 1998a; USDA, 2005). The farm-scale vegetation diversity (evaluated by the type of wheatbased crop system used) had a greater effect on parasitoid prevalence than the regional-scale vegetation diversity (see Fig. 5.3a). The findings were consistent with those of Thies et al. (2005), who determined that landscape structure at the spatial scale of $0.5-2.0 \mathrm{~km}$ (approximates our farm scale) had the most significant influence on cereal aphid parasitoids.

In addition, the farm- and regional-scale factorial design of plant diversity revealed that parasitoid abundance in homogeneous areas especially benefited from 
landscape variable (percentage of arable land). By comparing $F$-statistics and levels of significance among the seven spatial scales analysed, the scale associated with the highest explanatory power in the regression was determined.

The advantage of using a classification gradient in a complete factorial design is its ability to show relative contributions and interactions (joint effects) between scales that are relevant to agricultural management interests. Using the North American Great Plains cereal aphid example, a more complex wheat-based system that included a spring-sown annual crop was a good strategy to promote parasitoids, and the approach was especially important in the more grass-based homogeneous regions of the study area (see Fig. 5.3).

The implication from a cropping system perspective is that farmers, especially in highly homogeneous vegetation areas, can enhance parasitoids by diversifying their wheat strip crop system. Schmidt et al. (2005) also utilized a factorial design to differentiate effects of local management and wider landscape context on ground-dwelling farmland spiders. In contrast, the regression approach has benefits in finer-scale discrimination of the functioning of PPNE interactions. Thies et al. (2005) concluded that smaller spatial scales were more relevant for cereal aphid parasitoids (0.5$2.0 \mathrm{~km}$ ) as compared with spatial scales relevant for dispersal of cereal aphids (up to $6.0 \mathrm{~km}$ ) within the spatial scales studied. Not surprisingly, the major finding of the two analytical approaches in these studies of cereal aphids was consistent, with the differences reflecting the intent of the studies. For both, local vegetation, whether actively managed by a farmer or extant, is the scale most closely associated with parasitoid abundance.

\section{Practitioner Support in Areawide Application of Vegetation- based Management}

In practice, within-field and near-field manipulation of vegetation has benefited from understanding of PPNE interactions (Powell, 1986; Barbosa, 1998). Regionally, extant vegetation may be associated with differing risks to pests, because of different levels of pest management service related to different levels of plant diversity found across the agroecosystem (Marino and Landis, 1996; Elliott et al., 1998b; Thies et al., 2005). Conceptually, this information is useful in encouraging farmer adoption of land management practices and regional land use planning that will be most likely to preserve and enhance pest management services, as well as to reverse the trend of biodiversity loss in major agricultural zones of the world.

From a practitioner perspective, pest managers are being encouraged through incentives mechanisms (Casey et al., 1999) and challenged through regulatory mechanisms (Johnson and Bailey, 1999) to adopt ecologically and vegetation-based IPM practices. The European Union, Canada and the USA, among others, have begun to institute conservation policies affecting growers (Casey et al., 1999; Anon., 2006; Hoard and Brewer, 2006). Both financial and technical assistance through governmental conservation programmes are available to growers to encourage adoption of specific IPM practices on farms that are linked to conservation of natural resources and ecosystem services (Anon., 2006; Hoard and Brewer, 2006). More detailed 
regional planning efforts to optimize ecosystem services, including pest management, are less structured in governmental programmes, but the potential impact of widespread grower participation in such programmes, such as the impact on agriculture and wildlife conservation of the Conservation Reserve Program in the Great Plains of North America (Mitchell, 1988), cannot be understated.

\section{Summary of Value of a Landscape Perspective to Pest Management}

Understanding the role of vegetation may facilitate on-farm, vegetation-based recommendations to improve pest management, assessment of benefits of regional plant diversity to pest management, or both. The former, specific vegetation-based recommendations for grower adoption, certainly have on-farm value. The latter has obvious implications for areawide pest management, either accumulating the effects of local vegetation structure in and around agricultural fields or in a synergistic or detrimental fashion where regional plant diversity constrains the interactions at lower organizational levels (Noss, 1990).

For areawide pest management application, local vegetation management recommendations applied regionally may show simple additive improvements to pest management, or the regional vegetation composition and structure may further enhance (or impede) beneficial PPNE interactions. Neutral or enhanced benefits serve areawide pest management, although the potential for capturing pest management enhancements areawide is of special interest to planning cropping system deployment strategies and adoption of vegetation-based farm practices. In our cereal aphid examples, the local farm-scale effect of vegetation management was clear in work from Germany, the UK and North America. And, in the case of the North American example, farm-scale crop diversification had special appeal in areas where the vegetation was regionally homogeneous.

The dilemma for pest managers interested in areawide pest management and vegetation-based management approaches is that opportunities and complexity are probably highest when there are available a diverse fauna and diverse agricultural landscape. This diversity begs the question of how we may use composition and structure of extant managed and unmanaged lands to support pest management services; and how additional farm- or regional-scale management shifts can further benefit pest management. A landscape perspective, and a trend toward more quantitative analytical methods and more readily accessible land cover products, may become increasingly valuable as conservation and other societal interests encourage practitioners to use vegetation management as a tool to manage pests, locally and areawide.

\section{Acknowledgements}

We appreciate the financial support of the USDA CSREES National Research Initiative, Biologically based Pest Management Program (grants 2000- 02559 and 2002- 04573). 
We thank the University of Wyoming, grower cooperators and students (M. DeWine, S. Grabowski, K. Hoff, A. Kelsey and S. Yan) for support and assistance in carrying out field studies in the wheat-growing west-central region of the Great Plains of North America. We thank Tim Johnson for producing Fig. 5.2. The views expressed herein are those of the authors only and do not necessarily reflect or represent the opinions, positions or policies of the US Department of Agriculture.

\section{References}

Ahern, R.G. and Brewer, M.J. (2002) Effect of different wheat production systems on the presence of two parasitoids (Hymenoptera: Aphelinidae, Braconidae) of the Russian wheat aphid in the North American Great Plains. Agriculture, Ecosystems and Environment 92, 201-210.

Altieri, M.A. (2004) Biodiversity and Pest Management in Agroecosystems. Food Products Press, New York, $236 \mathrm{pp}$.

Anon. (2006) Project Eligibility Guidelines for Environmental Cost-share Programs Available to Farmers through the Canada-Ontario Environmental Farm Plan. Agriculture and Agri-Food Canada, Guelph, Ontario, Canada, 23 pp.

Banks, J.E. (2000) Natural vegetation in agroecosystems: pattern and scale of heterogeneity. In: Ekbom, B., Irwin, M. and Robert, Y. (eds) Interchanges of Insects between Agricultural and Surrounding Landscapes. Kluwer Press, Dordrecht, Netherlands, pp. 215-229.

Barbosa, P. (1998) Conservation Biological Control. Academic Press, San Diego, California, 396 pp.

Benton, T.G., Vickery, J.A. and Wilson, J.D. (2003) Farmland biodiversity: is habitat heterogeneity the key? Trends in Ecology and Evolution 18, 182-188.

Boyle, H. and Barrows, E.M. (1978) Oviposition and host feeding behavior of Aphelinus asychis (Hymenoptera: Chalcidoidea: Aphelinidae) on Schizaphis graminum (Homoptera: Aphididae) and some reactions of aphids to this parasite. Proceedings of the Entomological Society of Washington $80,441-455$.

Brewer, M.J., Noma, T. and Elliott, N.C. (2005) Hymenopteran parasitoids and dipteran predators of the invasive aphid Diuraphis noxia after enemy introductions: temporal variation and implication for future aphid invasions. Biological Control 33, 315--323.

Casey, F., Schmits, A., Swinton, S. and Zilberman, D. (1999) Flexible Incentives for the Adoption of Environmental Technologies in Agriculture. Kluwer Academic Publishers, Norwell, Massachusetts, $370 \mathrm{pp}$.

Cowgill, S.E., Wratten, S.D. and Sotherton, N.W. (1993) The effects of weeds on the numbers of hoverfly (Diptera: Syrphidae) adults and the distribution and composition of their eggs in winter wheat. Annals of Applied Biology 123, 499-515.

De Farias, A.M.I. and Hopper, K.R. (1997) Responses of female Aphelinus asychis (Hymenoptera: Aphelinidae) and Aphidius matricariae (Hymenoptera: Aphidiidae) to host and plant-host odors. Environmental Entomology 26, 989-994.

Dennis, P., Fry, G.L.A. and Anderson, A. (2000) The impact of field boundary habitats on the diversity and abundance of natural enemies in cereals. In: Ekbom, B., Irwin, M. E. and Robert, Y. (eds) Interchanges of Insects Between Agricultural and Surrounding Landscapes. Kluwer Academic Publishers, Dordrecht, The Netherlands, pp. 195-214.

Donahue, J.D., Brewer, M.J. and Burd, J.D. (2000) Relative suitability of crested wheatgrass and other perennial grass hosts for the Russian wheat aphid (Homoptera: Aphididae). Journal of Economic Entomology 93, 323-330.

Duelli, P. (1997) Biodiversity evaluation in agricultural landscapes: an approach at two different scales. Agriculture Ecosystems and Environment 62, 81-91. 
Dunning, J.B., Danielson, B.J. and Pulliam, H.R. (1992) Ecological processes that affect populations in complex landscapes. Oikos 65, 169-175.

Elliott, N.C., Hein, G.L., Carter, M.R., Burd, J.D., Holtzer, T.O., Armstrong, J.S. and Waits, D.A. (1998a) Russian wheat aphid (Homoptera: Aphididae) ecology and modeling in Great Plains agricultural landscapes. In: Quisenberry, S.S. and Peairs, F.B. (eds) Response Model for an Introduced Pest - the Russian Wheat Aphid. Proceedings Thomas Say Publications in Entomology, Entomological Society of America, Lanham, Maryland, pp. 31-64.

Elliott, N.C., Kieckhefer, R.W., Lee, J. and French, B.W. (1998b) Influence of within-field and landscape factors on aphid predator populations in wheat. Landscape Ecology 14, 239-252.

Elliott, N.C., Lee, J.H. and Kindler, S.D. (1999) Parasitism of serveral aphid species by Aphelinus asychis (Walker) and Aphelinus albipodus Hayat and Fatima. Southwestern Entomologist 24, 5-12.

Fahrig, L. and Jonsen, I. (1998) Effect of habitat patch characteristics on abundance and diversity of insects in an agricultural landscape. Ecosystems 1, 197-205.

Fahrig, L. and Merriam, G. (1994) Conservation of fragmented populations. Conservation Biology $8,50-59$.

Fernandes, O.A., Wright, R.J., Baumgarten, K.H. and Mayo, Z.B. (1997) Use of rubidium to label Lysiphlebus testaceipes (Hymenoptera: Braconidae), a parasitoid of greenbugs (Homoptera: Aphididae), for dispersal studies. Environmental Entomology 26, 1167-1172.

Freemark, K. (2005) Farmlands for farming and nature. In: Wiens, J.A. and Moss, M.R. (eds) Issues and Perspectives in Landscape Ecology. Cambridge University Press, Cambridge, UK, pp. 193-200.

Helenius, J. (1997) Spatial scales in ecological pest management (EPM): importance of regional crop rotations. Biological Agriculture and Horticulture 15, 163-170.

Hoard, R.J. and Brewer, M.J. (2006) Adoption of pest, nutrient, and conservation vegetation management using financial incentives provided by a US Department of Agriculture Conservation Program. Hort Technology 16, 306-311.

Jensen, J.R. (2000) Remote Sensing of the Environment: an Earth Resource Perspective. Prince Hall, Upper Saddle River, New Jersey, 544 pp.

Jervis, M.A. (2005) Insects as Natural Enemies. Springer, Dordrecht, Netherlands, 748 pp.

Johnson, S.L. and Bailey, J.E. (1999) Food Quality Protection Act 1996: major changes to the Federal Food, Drug, and Cosmetic Act; the Federal Insecticide, Fungicide, and Rodenticide Act and impacts of the changes to pesticide regulatory decisions. In: Ragsdale, N.N. and Seiber, J.N. (eds) Pesticides: Managing Risks and Optimizing Benefits. American Chemistry Society, Washington, DC, pp. 8-15.

Jones, O.T. and Casagrande, E.D. (2000) The use of semiochemical-based devices and formulations in area-wide programmes: a commercial perspective. In: Tan, K. (ed.) Area-wide Control of Fruit Flies and Other Insect Pests. Penerbit Universiti Sains Malaysia, Penang, Malaysia, pp. 285-294.

Kaiser, M.E., Noma, T., Brewer, M.J., Pike, K.S., Vockeroth, J.R. and Gaimari, S.D. (2007) Hymenopteran parasitoids and dipteran predators found using soybean aphid after its Midwestern United States invasion. Annals of the Entomological Society of America 100, 196-205.

Kruess, A. and Tscharntke, T. (1994) Habitat fragmentation, species loss, and biological control. Science 264, 1581-1584.

Letourneau, D.K. (1998) Conservation biology: lessons for conserving natural enemies. In: Barbosa, P. (ed.) Conservation Biological Control. Academic Press, San Diego, California, pp. 9-38.

Marino, P.C. and Landis, D.A. (1996) Effect of landscape structure on parasitoid diversity and parasitism in agroecosystems. Ecological Applications 6, 276-284.

Mason, P.G. and Hopper, K.R. (1997) Temperature dependence in locomotion of the parasitoid Aphelinus asychis (Hymenoptera: Aphelinidae) from geographical regions with different climates. Environmental Entomology 26, 1416-1423. 
McGarigal, K. and Marks, B.J. (1995) FRAGSTATS: spatial pattern analysis program for quantifying landscape structure. USDA Forest Service General Technical Report, PNW-351, Fort Collins, Colorado, 134 pp.

Menalled, F.D., 'Marino, P.C., Gage, S.H. and Landis, D.A. (1999) Does agricultural landscape structure affect parasitism and parasitoid diversity? Ecological Applications 9, 634-641.

Mitchell,J.E. (1988) Impacts of the Conservation Reserve Program in the Great Plains: Symposium Proceedings. USDA Forest Service General Technical Report RM-158, Rocky Mountain Forest and Range Experiment Station, Fort Collins, Colorado, 134 pp.

Murphy, B.C., Rosenheim, J.A. and Granett, J. (1996) Habitat diversification for improving biological control: abundance of Anagrus epos (Hymenoptera: Mymaridae) in grape vineyards. Environmental Entomology 25, 495-504.

Nentwig, W. (1989) Augmentation of beneficial arthropods by strip-management II: successional strips in a winter wheat field. Journal of Plant Diseases and Protection 96, 89-99.

Noma, T., Brewer, M.J., Pike, K.S. and Gaimari, S.D. (2005) Hymenopteran parasitoids and dipteran predators of Diuraphis noxia in the west-central Great Plains of North America: species records and geographic range. BioControl 50, 97-111.

Noss, R.F. (1990) Indicators for monitoring biodiversity: a hierarchical approach. Conservation Biology 4, 355-364.

Pike, K.S., Starý, P., Miller, T., Graf, G., Allison, D., Boydston, L. and Miller, R. (2000) Aphid parasitoids (Hymenoptera: Braconidae: Aphidiinae) of North-west USA. Proceedings of the Entomological Society of Washington 102, 688-740.

Powell, W. (1986) Enhancing Parasitoid Activity in Crops. In: Waage, J. and Greathead, D. (eds) Insect Parasitoids. Academic Press, London, pp. 319-340.

Quicke, D.L.J. (1997) Parasitic Wasps. Chapman \& Hall, London, 470 pp.

Roland, J. and Taylor, P.D. (1997) Insect parasitoid species respond to forest structure at different spatial scales. Nature 386, 710-713.

Root, R.B. (1973) Organization of a plant-arthropod association in simple and diverse habitats: the fauna of collards (Brassica oleracea). Ecological Monographs 43, 95-124.

Schmidt, M.H., Thewes, U., Thies, C. and Tscharntke, T. (2004) Aphid suppression by natural enemies in mulched cereals. Entomologia Eperimentalis et Applicata 1 13, 87-93.

Schmidt, M.H., Roschewitz, I., Thies, C. and Tscharntke, T. (2005) Differential effects of landscape and management on diversity and density of ground-dwelling farmland spiders. Joumal of Applied Ecology 42, 281-287.

Schuster, D.J. and Starks, K.J. (1974) Response of Lysiphlebus testaceipes in an olfactometer to a host and a non-host insect and to plants. Environmental Entomology 3, 1034-1035.

Sheehan, W. (1986) Response by specialist and generalist natural enemies to agroecosystem diversification: a selective review. Environmental Entomology 15, 456-461.

Thies, C., Roschewitz, I. and Tscharntke, T. (2005) The landscape context of cereal aphid-parasitoid interactions. Proceedings of the Royal Society. B, Biological Sciences 272, 203-210.

USDA (2005) Agricultural statistics database. US Department of Agriculture, Beltsville, Maryland (http://www.nass.usda.gov/Census\&lowbar;of\&lowbar;Agriculture/index.asp).

USDA (2007) Cropland data layer. US Department of Agriculture, Beltsville, Maryland (htp://www.nass.usda.gov/research/Cropland/SARSla.htm).

Vorley, V.T. and Wratten, S.D. (1987) Migration of parasitoids (Hymenoptera: Braconidae) of cereal aphids (Hemiptera: Aphididae) between grassland, early-sown cereals and late-sown cereals in southern England. Bulletin of Entomological Research 77, 555-568.

Wissinger, S.A. (1997) Cyclic colonization in predictably ephemeral habitats: a template for biological control in annual crop systems. Biological Control 10, 4-15. 